\title{
Patterns of Medicare-funded primary health and specialist consultations in Aboriginal and non-Aboriginal Australians in the two years before hospitalisation for ischaemic heart disease
}

Tiew-Hwa Katherine Teng ${ }^{1 *}$, Judith M. Katzenellenbogen ${ }^{1,2}$, Elizabeth Geelhoed ${ }^{3}$, Anthony S. Gunnell2, Matthew Knuiman ${ }^{2}$, Frank M. Sanfilippo ${ }^{2}$, Joseph Hung ${ }^{4}$, Qun Mai ${ }^{2,5}$, Alistair Vickery ${ }^{6}$ and Sandra C. Thompson ${ }^{1}$

\begin{abstract}
Background: Ischaemic heart disease (IHD) remains the leading cause of morbidity and mortality for both Aboriginal and non-Aboriginal Australians. Patterns of primary and specialist care in patients leading up to the first hospitalisation for IHD potentially impact on prevention and subsequent outcomes. We investigated the differences in general practice (GP), specialist and emergency department (ED) consultations, and associated resource use in Aboriginal and non-Aboriginal people in the two years preceding hospitalisation for IHD.

Methods: Linked-data were used to identify first IHD admissions for Western Australians aged 25-74 years in 2002-2007. Person-linked GP, specialist and ED consultations were obtained from the Medicare Benefits Schedule (MBS) and ED records to assess health care access and costs for the preceding 2 years.

Results: Aboriginal people constituted 4.7\% of 27,230 IHD patients, 3.5\% of 1,348,238 MBS records, and 14\% of 33,170 ED presentations. Aboriginal (vs. non-Aboriginal) people were younger (mean 50.2 vs 60.5 years), more commonly women (45.2\% vs $28.4 \%$ ), had more comorbidities [Charlson index $\geq 1,35.2 \%$ vs $26.3 \%$ ], were more likely to have had GP visits (adjusted rate-ratio 1.07, 95\% Cl 1.02-1.12), long/prolonged (16.0\% vs 11.9\%) consults and non-vocationally registered GP consults (17.1\% vs 3.2\%), but less likely to received specialist consults (mean 1.0 vs 4.1). Mean number of urgent/semiurgent ED presentations in the year preceding the IHD admission was higher in Aboriginal people (2.9 vs 1.9). Aboriginal people incurred $2.7 \%$ of total associated MBS expenditure (estimated at $\$ 59.7$ million). Mean total cost per person was 43. $3 \%$ lower in Aboriginal patients, with cost differentials being greatest in diabetic and chronic kidney disease patients.

Conclusions: Despite being over-represented in urgent/semi-urgent ED presentations and admissions for IHD, Aboriginal people were under-resourced compared with the rest of the population, particularly in terms of specialist care prior to first IHD hospitalisation. The findings underscore the need for better primary and specialist shared care delivery models particularly for Aboriginal people.
\end{abstract}

Keywords: Health care disparity, Aboriginal health, Indigenous health services, Ischaemic heart disease, Administrative datasets, Primary health care

\footnotetext{
* Correspondence: katherine.teng.t.h@nhcs.com.sg

${ }^{1}$ Western Australian Centre for Rural Health, School of Population and Global Health, The University of Western Australia (M431), 35 Stirling Highway, Perth, WA 6009, Australia

Full list of author information is available at the end of the article
}

(c) The Author(s). 2018 Open Access This article is distributed under the terms of the Creative Commons Attribution 4.0 International License (http://creativecommons.org/licenses/by/4.0/), which permits unrestricted use, distribution, and reproduction in any medium, provided you give appropriate credit to the original author(s) and the source, provide a link to the Creative Commons license, and indicate if changes were made. The Creative Commons Public Domain Dedication waiver (http://creativecommons.org/publicdomain/zero/1.0/) applies to the data made available in this article, unless otherwise stated. 


\section{Background}

Ischaemic heart disease (IHD) remains the leading cause of morbidity and mortality for both Aboriginal and non-Aboriginal populations $[1,2]$. The imperative to prevent the first episode of IHD remains strong given that sudden cardiac death occurs on first presentation for one in five [3]. Chronic diseases account for $70 \%$ of the gap in total disease burden between Aboriginal and non-Aboriginal Australians [4]. Despite medical advances, cardiovascular disease (CVD) contribute one-fifth of the differential in total disease burden between Aboriginal and non-Aboriginal Australians [4], with greater burden of chronic diseases, such as diabetes and chronic kidney disease (CKD) in the former subpopulation [5].

In Australia, private and public health services exist side by side, with private health insurance (covering part costs of private hospital and specialist services) only accessed by those who can afford to pay. Through Australia's universal health insurance scheme, public hospital inpatient and outpatient services are free to patients. Primary care services are substantially subsidised through Medicare, both in mainstream services and Aboriginal Medical Services [6], which include additional schemes to better meet Aboriginal health needs [7, 8], e.g. reduced cost of prescribed medicines through Closing the Gap scheme. In Western Australia, medical specialist services are concentrated in Perth, the capital city, with most of the rural population (including $60 \%$ of the Aboriginal population) needing to travel considerable distances for access. Rural services have difficulties in attracting health professionals, with workforce retention a further challenge. Despite the fact that Aboriginal Australians have access to primary care through multiple avenues, a recent cost analysis highlighted that $60 \%$ of the health expenditure on Aboriginal Australians was on secondary care in public hospitals [9]. However, primary health care (Medicare services and medicines) expenditure per person was significantly less than for non-Aboriginal Australians [9, 10], suggesting underinvestment of funds into prevention, early intervention, secondary prevention and community services for Aboriginal people [10].

General practitioners (GPs) in primary care serve as the gatekeeper to the health system in Australia. GPs have a critical role in the primary prevention of IHD [11], and are ideally situated to provide secondary prevention [11]. The integration between primary, specialist and tertiary care, as a basis of seamless continuity of care is of paramount importance for these patients [11]. GP shortages are however greater in non-metropolitan regions where the majority of Aboriginal people reside [12]. Consequently, policies exist to boost GP numbers in rural areas through financial incentives, and international medical graduates (IMGs) are provided restricted registration to work in areas of unmet need [12]. General practice is recognised as a medical specialty through the General Practice Vocational Register. GPs who have completed their fellowship are vocationally registered (VR GPs) and have access to higher Medicare rebates, while those who are not (Non-VR GPs) utilise lower Medicare rebates except under special programs such as districts of workforce shortage which commonly occurs in disadvantaged and remote areas.

Medicare-rebated (private) specialist services often incur significant co-payment such that patients who experience financial difficulties are under-represented in such practices, relying on hospital out-patient consultations. People who live in rural/remote areas often have limited access to private specialists and are required to travel long distances to access public hospital out-patient services.

Patterns of primary and specialist care in patients leading up to the first admission with IHD potentially impacts on prevention and subsequent outcomes. We aimed to compare the patterns of GP and out-of-hospital specialist consultations, and direct costs of these services in Aboriginal and non-Aboriginal patients in Western Australia (WA) in the 2 years preceding first hospitalisation for IHD. Additionally, we investigated the use of emergency departments (ED) as a substitute for primary health care services.

\section{Methods}

\section{Study population}

A cohort of WA residents aged 25-74 years was identified from administrative hospital data based on first-ever hospitalisation (15-year clearance period) for IHD as a principal discharge diagnosis ('index hospitalisation') during the period 2002-2007. IHD was identified from codes I20-I25 of the International Classification of Diseases 10th edition Australian Modification.

\section{Data sources}

Linked state-wide inpatient records from the Hospital Morbidity Data Collection (HMDC) and Emergency Department Data Collection (EDDC) data were obtained from the WA Data Linkage System [13]. National government-held Medicare Benefits Schedule (MBS) data provided details of professional consultations, procedures and diagnostic tests for citizens/permanent residents that universally claim from Medicare. The MBS data do not cover pharmaceutical claims (separate scheme) or outpatient services provided by public hospitals.

\section{Identification of services and costs}

HMDC records were merged with MBS data (20002007) to identify the Medicare records for 2 years preceding the index hospitalisation. GP and specialist consultations were identified, and associated costs were compared between Aboriginal and non-Aboriginal 
patients using the bottom-up itemised MBS costs (scheduled fees). Additional resource costs were estimated by applying costs derived from the MBS for ambulatory community consultations and associated pathology and imaging tests. Person-based costs were aggregated and compared for the two sub-populations. Only direct health care (service provision) costs were examined. The historical consumer price index was used to adjust for changes in costs (2005 as base year).

Similarly, ED presentations in the 2 years preceding the first hospitalisation were identified and relevant data extracted, including demographic and episode fields with presentation time/date and triage scores ( $\leq 3$ represent immediate/urgent cases; $4=$ semi-urgent; 5 = non-urgent) [14].

\section{Demographic and co-morbidity data}

To optimise the estimation of Aboriginal status in routinely-collected data $[15,16]$, a patient was defined as being Aboriginal if $\geq 25 \%$ of their historical hospital admissions had been coded as Aboriginal. We have used the same definition in previous publications to acknowledge under ascertainment in hospital administrative data collections while avoiding over-inclusion [17, 18]. The Charlson comorbidity index was calculated using the modified Deyo algorithm [19] and individual comorbidities (Table 1) identified using a 5-year look-back period. The Accessibility/Remoteness Index of Australia (ARIA) [20] classifies five categories of residential remoteness and was included as a covariate in the regression analysis. Separately, the greater Perth metropolitan city definition [21] dichotomised place of residence into metropolitan and rural residence. Private health medical insurance status recorded in the HMDC was used as a proxy for socio-economic status.

\section{Statistical analyses}

Baseline characteristics and crude mortality by Aboriginal status were compared using descriptive statistics. Results are provided for broad age groups $<55$ and $\geq$ 55 years, with 55 years as the median age of the patients. Two-tailed t- or Mann-Whitney tests (for continuous variables) and the Pearson chi-squared test (for categorical variables) were used to test for significance. Negative binomial regression log-linear models were used to model count of GP consults or specialist consults as separate dependent variables in the 2 years preceding IHD admission, with adjustment for covariates at index admission. This method was selected because the distribution of our count data showed that it was over-dispersed (highly skewed) and not suitable for Poisson regression models which assume the variance is equal to the mean. Stratified analyses [by gender, broad age group, metropolitan (vs rural), incident (vs prevalent), diabetes and
CKD status] were undertaken to determine the differential in subgroups and to identify where the need for intervention was most critical. STATA version 13.1 was used for analyses.

\section{Results}

\section{Patient characteristics}

Of 28,331 hospitalised IHD patients identified, 1101 (7.4\% Aboriginal) had no MBS records and were excluded. The final cohort comprised 27,230 patients (4.7\% Aboriginal; 85\% with first-ever IHD admissions). Aboriginal patients were more likely to be: younger (65.6\% < 55 years vs $25.8 \%$ non-Aboriginal); women (45.2\% vs $28.4 \%)$; from very remote areas $(39.8 \%$ vs $3.1 \%$ ); to present with acute forms of IHD (acute MI or unstable angina); and have greater comorbidity burden (Table 1). Non-Aboriginal patients were more likely to have private health insurance (Table 1). Mortality following an ischaemic event was higher in Aboriginal patients in the first year after admission (5.5\% vs $3.0 \%$ Non-Aboriginal) but not significantly higher 30-days following (1.9\% vs $1.3 \%$ Non-Aboriginal).

\section{MBS expenditure and resource utilisation costs in subgroups}

A total of 1,348,238 relevant MBS claims (representing $\$ 59.7 \mathrm{M}$ in expenditure) were identified in the preceding 2 years, with $3.5 \%(47,047)$ attributed to Aboriginal patients, $(2.7 \%$ of expenditure) (Table 2). The mean total Medicare expenditure per person was $43.3 \%$ lower in Aboriginal patients ( $\$ 1271$ vs $\$ 2238$ non-Aboriginal). Differences in expenditure for Aboriginal and non-Aboriginal patients ranged by sub-group, from $26.9 \%$ lower in age group $<55$ years, $52.6 \%$ lower in diabetic patients and 49.6\% lower in those with CKD. The difference persisted when restricted to metropolitan patients. For both Aboriginal and non-Aboriginal patients, costs were significantly higher in the year closest to the index event compared to 2nd year (56.3\% vs $43.7 \%$ ) preceding index admission.

\section{Medicare-derived specialty and professional consults}

Aboriginal patients had more GP records as a proportion of total records (Fig. 1) compared with non-Aboriginal patients $(60.4 \%$ vs $43.8 \%, p<0.001)$, although mean GP consults were not significantly different. Compared to non-Aboriginal people, Aboriginal people were 6.4 times more likely to see non-VR GPs, $69 \%$ less likely to see a specialist, $67 \%$ less likely to have surgery, 35\% less likely to have diagnostic imaging and $21 \%$ less likely to have pathology tests.

Aboriginal people were more likely to have had a long/ prolonged consult [defined as 'long': > 25 min; 'prolonged': $>45$ min' consultation) $16.0 \%$ vs $11.9 \%$ of total GP records]. More non-Aboriginal patients received Medicare-funded 


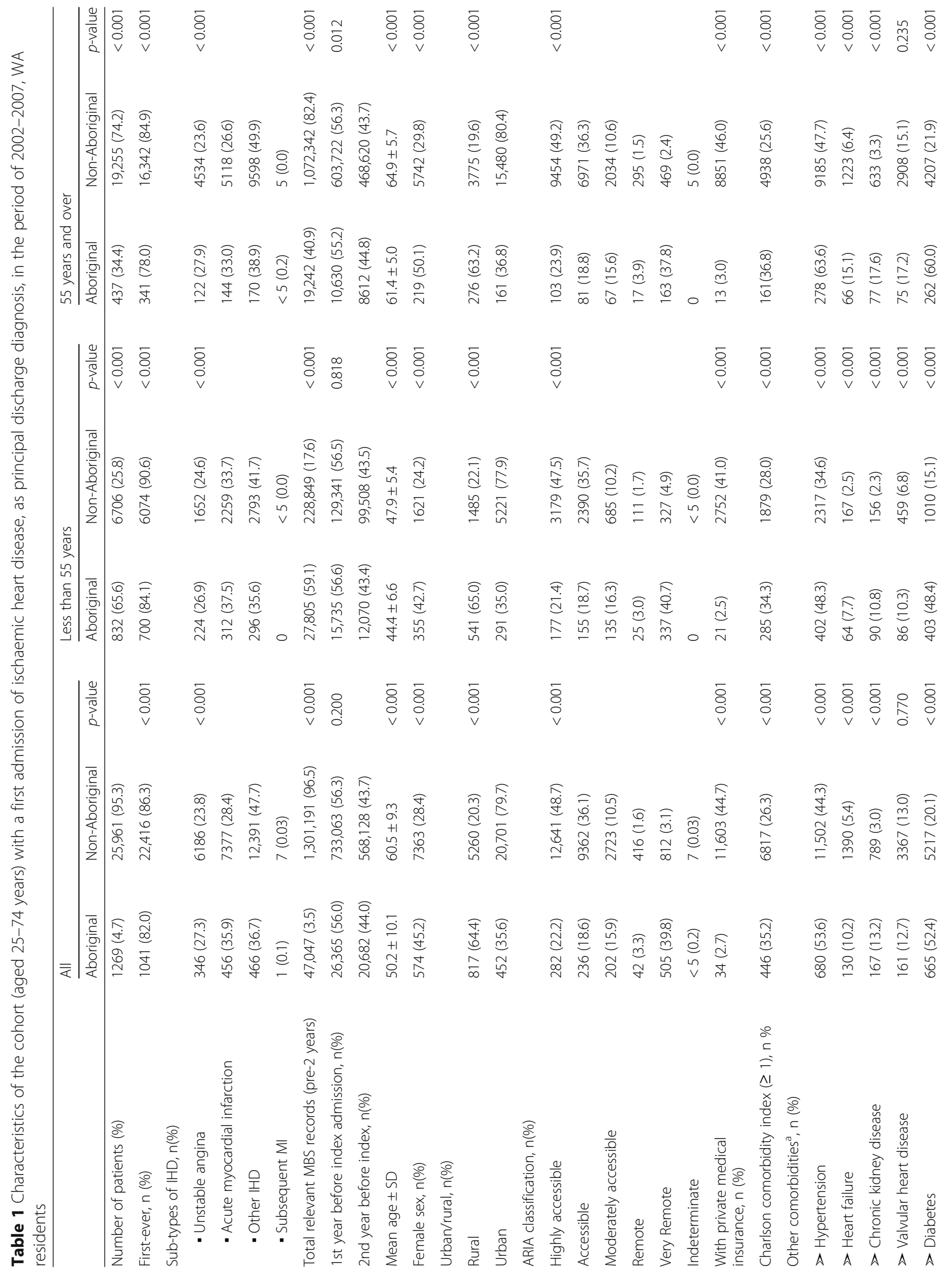




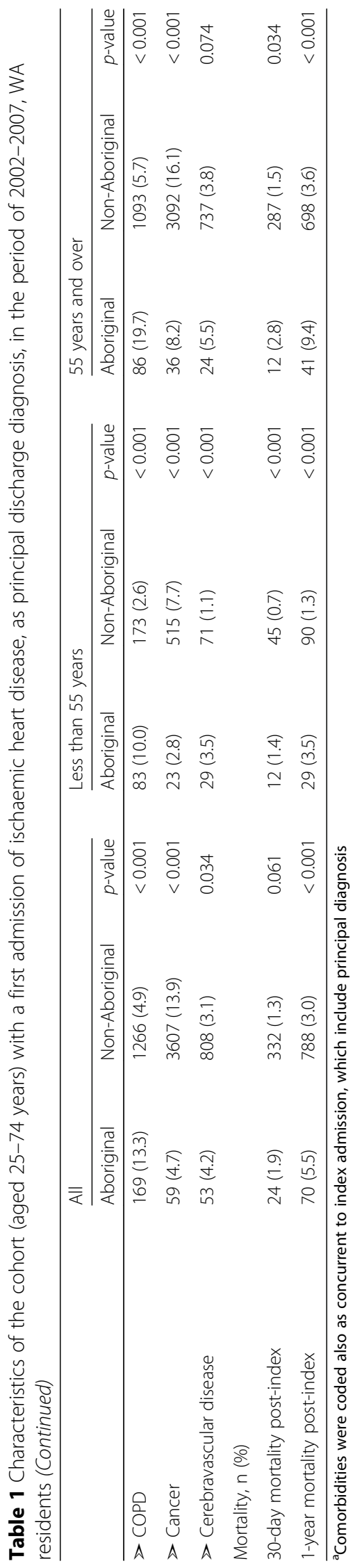


Table 2 Costs of resource utilisation in the 2 years preceding index IHD admission stratified by subgroups

\begin{tabular}{llll}
\hline & $\begin{array}{l}\text { Aboriginal } \\
(1)\end{array}$ & $\begin{array}{l}\text { Non-Aboriginal } \\
(2)\end{array}$ & $\begin{array}{l}\text { Ratio } \\
(1 / 2)\end{array}$ \\
\hline $\begin{array}{l}\text { Total healthcare expenditure } \\
\text { on the MBS items in 2 years } \\
\text { preceding index admission, }\end{array}$ & $1,613,868$ & $\begin{array}{l}58,100,000 \\
(2.7)\end{array}$ & \\
CPI adjusted, \$(\%) & & & \\
Mean healthcare cost/person & $1271 \pm 1391$ & $2238 \pm 2319$ & 0.57 \\
- Younger age <55 & $1134 \pm 1360$ & $1551 \pm 1885$ & 0.73 \\
- 55 years and older & $1532 \pm 1412$ & $2477 \pm 2406$ & 0.62 \\
- Men & $1049 \pm 1195$ & $2067 \pm 2183$ & 0.51 \\
- Women & $1541 \pm 1556$ & $2670 \pm 2582$ & 0.58 \\
- Metro patients & $1454 \pm 1424$ & $2332 \pm 2382$ & 0.62 \\
- Rural patients & $1170 \pm 1363$ & $1869 \pm 2013$ & 0.63 \\
- Incident patients & $1186 \pm 1197$ & $2099 \pm 2178$ & 0.56 \\
- Diabetic patients & $1461 \pm 1358$ & $3082 \pm 2572$ & 0.47 \\
- Chronic kidney disease & $1551 \pm 1445$ & $3079 \pm 2667$ & 0.50 \\
$\quad$ patients & & & \\
\hline
\end{tabular}

specialist consults (71.6\% vs $35.0 \%$ ), with a higher mean number of specialist consults (mean 4.1 vs 1.0). Mean GP costs per patient were slightly higher in Aboriginal patients (\$696 vs \$653) but mean Medicare-funded specialist costs were significantly lower in Aboriginal patients (Table 3). These patterns of GP and specialist consults were similar in metropolitan and rural residents.

More non-Aboriginal (vs Aboriginal) patients consulted a GP in the 30 days before first IHD admission
(12.6\% vs $10.9 \%, p<0.001)$. In the year preceding first IHD admission, the median time between last GP visit and index admission was slightly (but significantly) longer for Aboriginal patients [161 (IQR 74-264) vs 159 (IQR 69-260)] days. Specific MBS items for Aboriginal and telehealth services were examined but the counts were relatively low, as the period (2000-2007) pre-dated Medicare funding for telehealth.

\section{ED presentations}

$59.3 \%$ of non-Aboriginal patients (vs $86.4 \%$ Aboriginal) had prior ED records. Of $33,170 \mathrm{ED}$ attendances in the 2 years preceding IHD, 14\% were attributed to Aboriginal patients. Aboriginal (vs non-Aboriginal) patients had higher mean ED visits (4.3 vs 2.6), $p<0.001$. When restricted to urgent/semi-urgent attendances, mean number of ED presentations was higher in Aboriginal people (2.9 vs 1.9). Furthermore, the mean interval from the last urgent ED presentation to index admission was shorter in Aboriginal patients (27.9 vs 37.4 days, $p<0.001$ ), respectively.

\section{Independent predictors of GP and specialist consults}

Increasing age, female sex and comorbidities were all independently associated with higher rates of GP and specialist consults (Table 4). Heart failure and cerebrovascular disease, however, were associated with increased rates of GP but not Medicare-funded specialist consults. Private medical insurance was the strongest independent predictor of increased specialist service usage. Notably, there was a

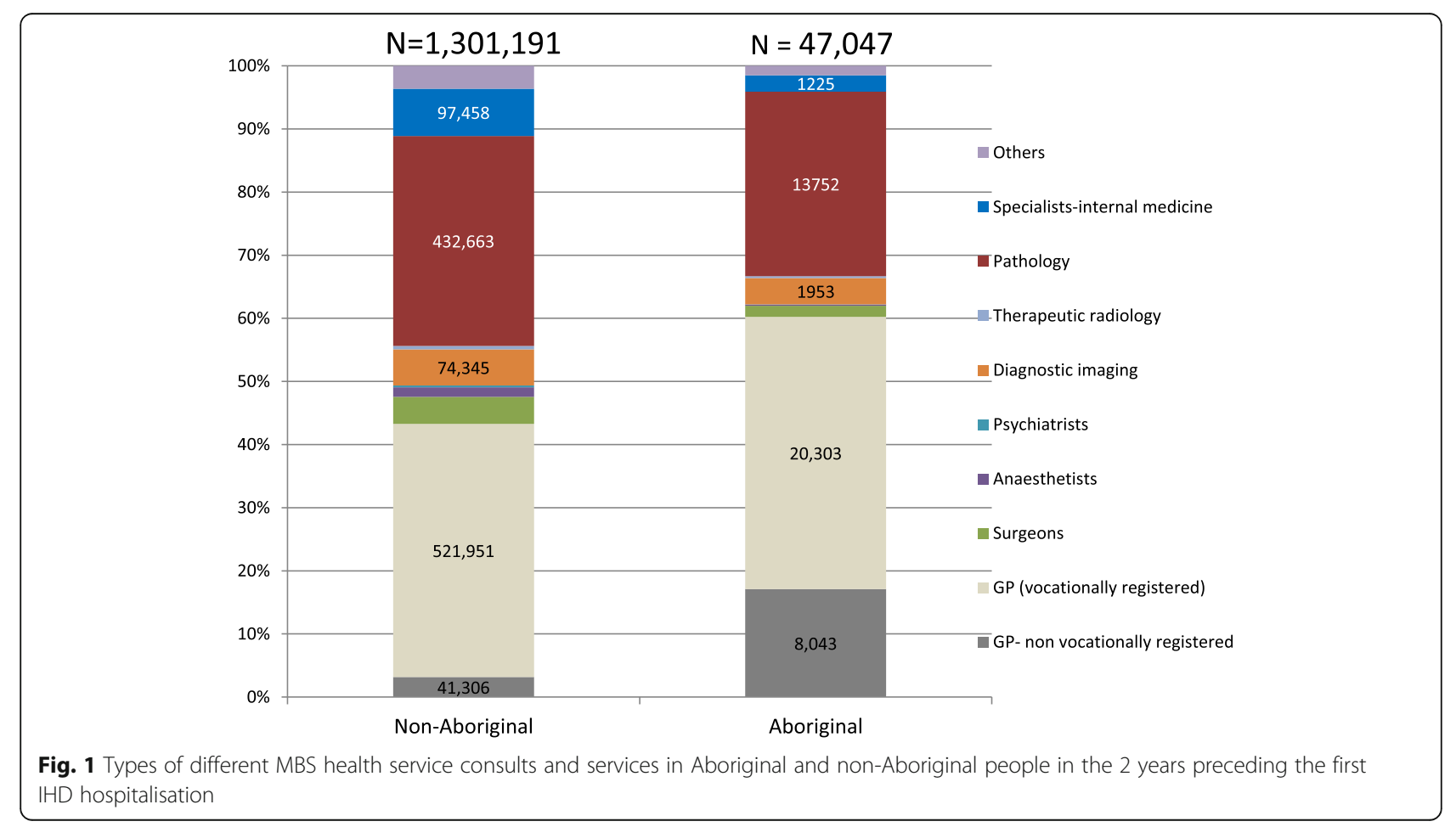




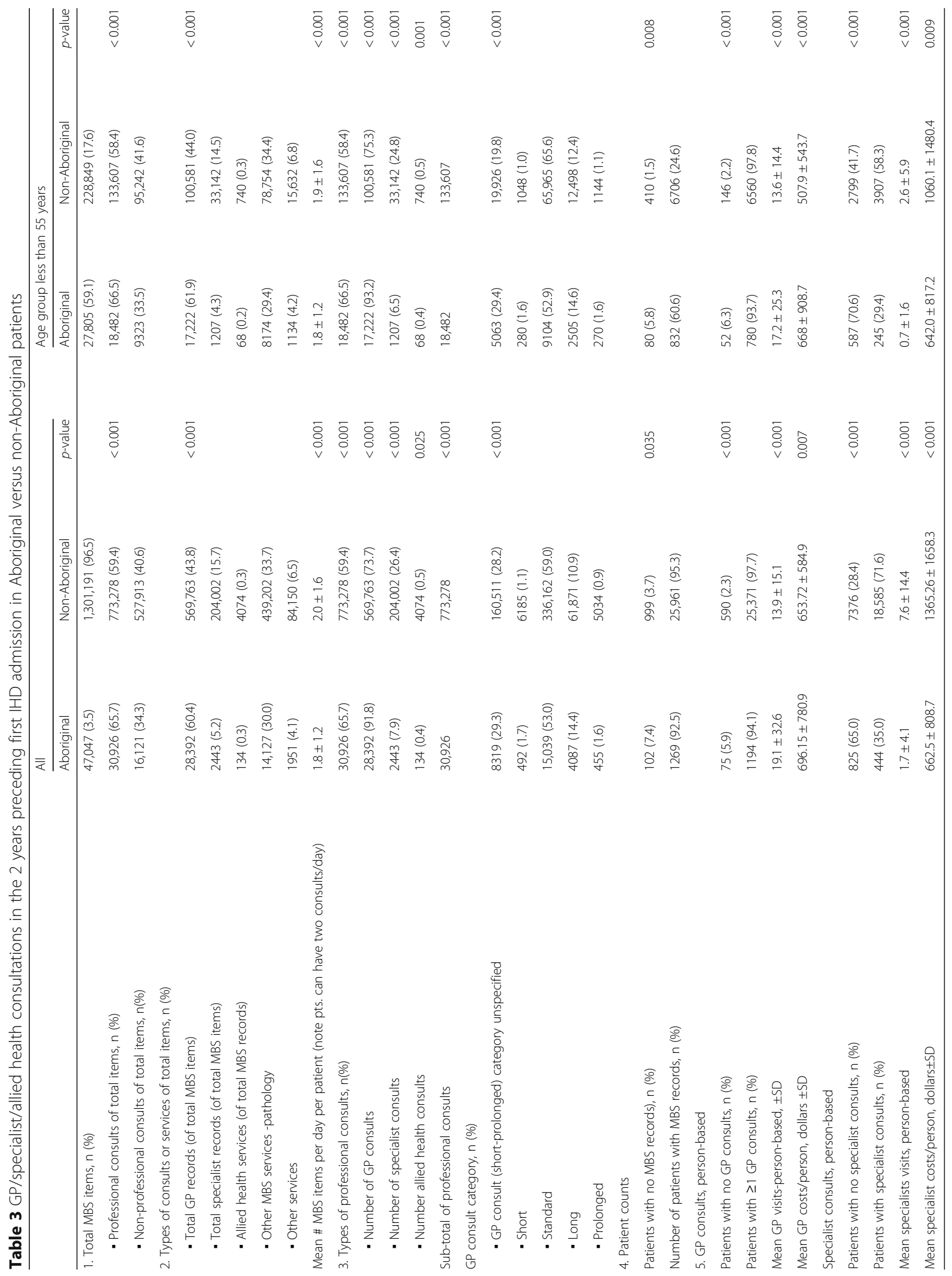


Table 4 Multivariable models using negative binomial regression for rates of GP visits (truncated at max 104, allowing maximum of 1 GP visit per week) and specialist consults over 2 years prior to first IHD admission $(n=27,230)$

\begin{tabular}{|c|c|c|c|c|c|c|c|c|}
\hline \multicolumn{5}{|l|}{ Multivariable model for GP consults } & \multicolumn{4}{|c|}{ Multivariable model for specialist consults } \\
\hline \multirow{2}{*}{$\frac{\text { GP visits (truncated) }}{\text { Age at admission }}$} & \multirow{2}{*}{$\frac{\mathrm{IRR}}{1.02}$} & \multirow{2}{*}{$\frac{p \text {-value }}{<0.001}$} & \multicolumn{2}{|l|}{$95 \% \mathrm{Cl}$} & \multirow{2}{*}{$\frac{\mathrm{IRR}}{1.03}$} & \multirow{2}{*}{$\frac{p \text {-value }}{<0.001}$} & \multicolumn{2}{|c|}{$95 \% \mathrm{Cl}$} \\
\hline & & & 1.02 & 1.02 & & & 1.02 & 1.03 \\
\hline Female gender & 1.32 & $<0.001$ & 1.30 & 1.35 & 1.32 & $<0.001$ & 1.28 & 1.37 \\
\hline Year of admission & 0.96 & $<0.001$ & 0.95 & 0.96 & 0.95 & $<0.001$ & 0.94 & 0.96 \\
\hline Aboriginal status (1) & 1.07 & 0.004 & 1.02 & 1.12 & 0.44 & $<0.001$ & 0.40 & 0.48 \\
\hline With private medical insurance & 0.90 & $<0.001$ & 0.88 & 0.92 & 1.81 & $<0.001$ & 1.75 & 1.86 \\
\hline \multicolumn{9}{|l|}{ ARIA classification } \\
\hline Highly accessible & 1.00 & & & & 1.00 & & & \\
\hline Accessible & 0.93 & $<0.001$ & 0.91 & 0.94 & 0.92 & $<0.001$ & 0.89 & 0.96 \\
\hline Moderately accessible & 0.82 & $<0.001$ & 0.79 & 0.84 & 0.80 & $<0.001$ & 0.76 & 0.84 \\
\hline Remote & 0.86 & $<0.001$ & 0.80 & 0.92 & 0.82 & 0.002 & 0.72 & 0.93 \\
\hline Very remote & 0.66 & $<0.001$ & 0.63 & 0.69 & 0.44 & $<0.001$ & 0.40 & 0.48 \\
\hline \multicolumn{9}{|l|}{ Comorbidities } \\
\hline Heart failure & 1.04 & 0.031 & 1.00 & 1.09 & 1.02 & 0.629 & 0.95 & 1.09 \\
\hline Chronic kidney disease & 1.19 & $<0.001$ & 1.13 & 1.25 & 1.53 & $<0.001$ & 1.40 & 1.66 \\
\hline Hypertension & 1.17 & $<0.001$ & 1.15 & 1.19 & 1.07 & $<0.001$ & 1.03 & 1.10 \\
\hline Rheumatic/valvular heart disease & 1.14 & $<0.001$ & 1.11 & 1.17 & 1.25 & $<0.001$ & 1.20 & 1.31 \\
\hline Diabetes & 1.33 & $<0.001$ & 1.30 & 1.36 & 1.47 & $<0.001$ & 1.41 & 1.53 \\
\hline COPD & 1.42 & $<0.001$ & 1.37 & 1.48 & 1.42 & $<0.001$ & 1.33 & 1.52 \\
\hline Cancer & 1.2 & $<0.001$ & 1.17 & 1.23 & 1.71 & $<0.001$ & 1.63 & 1.78 \\
\hline Cerebrovascular disease & 1.29 & 0.002 & 1.10 & 1.51 & 1.23 & 0.145 & 0.93 & 1.63 \\
\hline Stroke & 0.98 & 0.835 & 0.83 & 1.16 & 1.04 & 0.817 & 0.77 & 1.39 \\
\hline Coronary heart disease & 0.77 & $<0.001$ & 0.70 & 0.83 & 0.71 & $<0.001$ & 0.61 & 0.82 \\
\hline Charlson index & 0.89 & $<0.001$ & 0.88 & 0.9 & 0.88 & $<0.001$ & 0.86 & 0.89 \\
\hline
\end{tabular}

IRR = incidence rate ratio; $95 \% \mathrm{Cl}=95 \%$ confidence interval

Notes: For age group under 55 years and separately, in patients 55 years and older, there was no significant difference between Aboriginal and non-Aboriginal patients for GP visits (truncated at 104). When restricted to only metropolitan patients, Aboriginal patients had an adjusted IRR of only 0.36 ( $95 \%$ CI $0.31-0.42, p<$ 0.001 ) for specialist visits (as a count variable). Having private medical insurance was negatively associated with GP visits but positively with specialist visits, the IRR is $1.84(95 \% \mathrm{Cl} 1.77-1.90)$ compared with those without private medical insurance

declining gradient of GP and specialist consultations as residential postcodes became more remote (Table 4). In the fully adjusted model, Aboriginal status was associated with a slightly higher IRR of 1.07 (95\% CI 1.02-1.12) for GP consults but an IRR of 0.44 (95\% CI 0.40-0.48) for Medicare-rebated specialist consults. The latter IRR reduced further to 0.36 when the analysis was restricted to only metropolitan patients.

\section{Discussion}

This person-level, population-based study investigated the patterns of Medicare-funded GP and specialist care, and resource utilisation for Aboriginal and non-Aboriginal patients in the 2 years preceding first IHD hospitalisation. Our findings show that, after adjustment, Aboriginal patients were more likely to have had a GP consultation, a long/ prolonged consult and consult a non-VR GP, while substantially fewer received Medicare-rebated specialist consultations. The mean cost differential on Medicare expenditure over 2 years was 43.3\% lower in Aboriginal compared to non-Aboriginal people, despite higher prevalence of multimorbidity in Aboriginal patients. This difference persisted in metropolitan subgroups. Notably, the resource differential was greatest in diabetic and CKD patients for whom ongoing specialist expertise for managing complex care needs is arguably more critical. Private specialist consults were the key cost driver in Medicare expenditure differentials between Aboriginal and non-Aboriginal people. For ED presentations, Aboriginal patients, particularly those in rural/remote areas were more likely to use ED than GPs for conditions classified urgent/semi-urgent. These findings suggest a substitution effect of ED with primary care.

Published empirical evidence demonstrates the association between a strong primary care system and better health status, reduced hospitalisation, and all-cause (and 
CVD) mortality [22-24]. Further, evolving research suggests that a collaborative multidisciplinary approach based on the integration of specialists and GPs could lead to better cardiovascular outcomes in primary care setting, particularly for patients with multimorbidity [25]. In our study there was an over-representation of Aboriginal patients with no primary care records in the pre-event study period. Additionally, although Aboriginal patients had a marginally higher adjusted-IRR for primary consults, over a quarter of GP consults were rendered by non-VR GPs/IMGs. This might impact on the continuity and cultural appropriateness of care. IMGs are strongly represented in rural/remote Australia (particularly WA) [12] with many relocating from rural areas once licensing restrictions are satisfied [12, 26]. In a study of IMGs, Durey et al. [27] identified the need to better address cross-cultural issues and the importance of effective communication and building community and cross-institutional relationships. A strong physician-patient relationship (particularly developed in a culturally secure context), is a key element enabling continuity of care necessary for optimal management of chronic diseases, and might be limited in the current environment.

High performing general practices have lower IHD admission and mortality rates, with the association strongest for practices serving populations of high levels of economic deprivation [28]. This may lead to a reduction in the health inequalities noted in this analysis. Despite the initiatives to strengthen the GP sector in very remote areas, poor access to GP and both Medicare-funded and public hospital specialist services persists in very remote areas where the majority of Aboriginal people live. This highlights a critical need to create more innovative models of care.

Aboriginal patients, despite their younger average age, have significantly greater co-morbidity, adding considerably to complexities in managing the primary disease. This is often accompanied by complex social circumstances resulting from the unfortunate historical and political legacy of colonialism, with adversities including living in under-resourced remote locations (where access to medical care may be limited), poverty, unhealthy environments and higher rates of mental illness, imprisonment, poor educational attainment and family troubles [29]. This social, clinical and logistical complexity may explain the higher proportion of long/prolonged visits. Higher ED use among Aboriginal patients may reflect poor access to and/ or out-of-pocket costs of primary care (where ED is used as a proxy for primary care) as well as high clinical need. Comorbidities were all independent predictors of increased rates of GP consultations (Table 4). Consequently, Aboriginal (vs non-Aboriginal) patients have poorer 30-day and 1-year mortality outcomes, consistent with other reports $[16,17]$.
Rural disparities in Medicare expenditure for the financial year 2006-2007 were reflected in a total Medicare deficit of $\$ 811$ million [30], translating into 12.6 million fewer services during that year for the people of regional and remote areas, attributed largely to poorer access to health professionals. We have shown similar under-expenditure across the broad MBS service categories among Aboriginal patients, particularly in poorer access to specialist care. As Medicare-rebated specialist care does not cover public hospital out-patient services, the exact quantification of differential specialist utilisation could not be captured. Nevertheless, access to specialist care remains a significant issue for Aboriginal cardiac patients, often reflecting specialist shortages in rural areas, under-developed care pathways and weaknesses in communication/information flow between primary and acute and specialist care professionals - all of which impact on quality of care. Since 2010, Medicare has introduced a wide range for MBS items and rebates, including those for telehealth consultations for medical specialists in other locations, as a means to improve access. It is possible that greater uptake of such initiatives could address some of this gap.

More innovative models of care, incorporating appropriate telehealth, are needed to overcome the problems of costs and accessibility related to geographical location in WA. Additionally, this analysis shows structural reform of PHC services is needed to ensure better integration of care and management for Aboriginal people, over half of whom reside in rural Australia. Analysis of more contemporary data will be valuable to show how service utilisation has changed with recent health reforms.

\section{Strengths and limitations}

This study uses MBS data linked to a diagnostic cohort identified through hospital data, allowing individualised person-based utilisation of specific services and associated costs to be examined. Medicare data represent the most accurate and reliable source of health care attendance in Australia, although visits to an Aboriginal Medical Service could not be differentiated in provided data from mainstream consults. MBS data do not include outpatient consultations at public hospitals and the use of MBS data alone limits the true representation of specialist services provided. As Aboriginal patients are over-represented in the (mainly metropolitan) public outpatient clinics in WA and some specialist visits occur through alternative funding mechanisms, the difference in receipt of specialist ambulatory consults may be over-estimated. Improvement of out-patient hospital data to linkage standard is urgently required. Further, the MBS data is relatively old due to the long lead time needed for the requisition of Commonwealth data; regardless, the current analysis provides a base from which to gauge further improvements with 'Closing the Gap' initiatives undertaken by the government. 


\section{Conclusions}

Despite being over-represented in admissions for IHD, Aboriginal people were under-resourced compared with the rest of the population, particularly in terms of Medicare-funded specialist care. The differential in specialist consultations was the main driver of the difference in Medicare expenditure between the sub-populations. The disparity in resource utilisation is most marked among Aboriginal patients with diabetes and CKD, major contributors to premature illness and health costs. The findings underscore the need to further strengthen the continuity and integration of care (in and between primary and specialist care) for remote/very remote areas and for innovations in service delivery models involving shared primary and specialist care.

\begin{abstract}
Abbreviations
ARIA: Accessibility/Remoteness Index of Australia; CKD: Chronic kidney disease; CVD: Cardiovascular disease; ED: Emergency departments; EDDC : Emergency Department Data Collection; GP: General practitioners; HMDC: Hospital morbidity data collection; IHD: Ischaemic heart disease; IMGs: International medical graduates; MBS: Medicare benefits schedule; VR GPs: Vocationally registered general practitioners; WA: Western Australia
\end{abstract}

\begin{abstract}
Acknowledgements
The study was supported by a NHMRC project grant (\#1031057). Judith Katzenellenbogen is funded by an NHMRC Early Career Fellowship (\#037429). The Western Australian Centre for Rural Health receives funding from the Department of Health and Ageing. The authors thank the Western Australian Department of Health and the Australian Department of Health for providing the cross-jurisdictional linked data used in this study. We also thank the WA Data Linkage Branch and the staff of the Inpatient Data Collections for the provision of the data and the Registry of Births, Deaths and Marriages for providing the death data, and to the data custodian for the Emergency Department Data Collection. The inputs on Aboriginal MBS item codes from Dr. Marianne Woods and Ms. April Rutkay are much appreciated.
\end{abstract}

Use of any animal or human data or tissue

Not applicable.

\section{Funding}

The study had been supported by an NHMRC project grant (\#1031057). J Katzenellenbogen is funded by an NHMRC Early Career Fellowship (\#037429). The Western Australian Centre for Rural Health receives funding from the Department of Health and Ageing. The funding organisations did not have any role in the design of the study and data collection, analysis or interpretation of the data and writing of the manuscript.

\section{Availability of data and materials}

Please contact senior author, Professor Sandra C Thompson, for data requests.

\section{Authors' contributions}

All authors critically reviewed and contributed to the intellectual content of the manuscript. THKT, JMK, SCT, EG, MK, FMS and JH were involved with the conception of the study. Initial data preparation was done by ASG. THKT performed the statistical analyses, supported by MK and drafted the manuscript. SCT, AV and $\mathrm{JH}$ provided the clinical expertise. QM provided inputs on the use of cross-jurisdictional data. All authors have read and approved the final version of the manuscript.

\section{Ethics approval and consent to participate}

Ethics approvals were obtained from the WA Aboriginal Health Ethics Committee and the Human Research Ethics Committees of the University of WA and health departments of the Australian and WA governments. Approval for consent to participate was waived by the ethics committees as only de-identified administrative datasets were used and only aggregated data were presented.

\section{Consent for publication \\ Not applicable.}

\section{Competing interests}

The authors declare that they have no competing interests.

\section{Publisher's Note}

Springer Nature remains neutral with regard to jurisdictional claims in published maps and institutional affiliations.

\section{Author details}

${ }^{1}$ Western Australian Centre for Rural Health, School of Population and Global Health, The University of Western Australia (M431), 35 Stirling Highway, Perth, WA 6009, Australia. ${ }^{2}$ School of Population and Global Health, UWA, Perth, Australia. ${ }^{3}$ School of Allied Health, UWA, Perth, Australia. ${ }^{4}$ School of Medicine, Sir Charles Gairdner Hospital Unit, UWA, Perth, Australia. ${ }^{5}$ Department of Health, Perth, Western Australia, Australia. ${ }^{6}$ Division of General Practice, School of Medicine, Faculty of Health and Medical Sciences, UWA, Perth, Australia.

Received: 22 April 2018 Accepted: 17 July 2018

Published online: 02 August 2018

References

1. Finegold JA, Asaria P, Francis DP. Mortality from ischaemic heart disease by country, region, and age: statistics from World Health Organisation and United Nations. Int J Cardiol. 2013;168(2):934-45.

2. Nichols M, Townsend N, Scarborough P, Rayner M. Cardiovascular disease in Europe 2014: epidemiological update. Eur Heart J. 2014;35(42):2950-9.

3. Hobbs FD. Cardiovascular disease: different strategies for primary and secondary prevention? Heart. 2004;90(10):1217-23.

4. Australian Institute of Health and Welfare. Australian Burden of Disease Study: Impact and causes of illness and death in Aboriginal and Torres Strait Islander people 2011. Australian Burden of Disease Study series no. 6. Cat. no. BOD 7. Canberra: AlHW; 2016.

5. AlHW, Penm E. Cardiovascular disease and its associated risk factors in Aboriginal and TorresStrait Islander peoples 2004-05, 2008 Cardiovascular disease series no. 29. Cat. no. CVD 41 Contract No.: Cat. no. CVD 41. Canberra: AlHW; 2008.

6. Haynes E, Holloway M, Thompson SC. Survey findings of reporting requirements 2013. Report back to Aboriginal Community Controlled Health Services. Western Australian Centre for Rural Health, University of Western Australia, 2014.

7. Martin ME, Reath JS. General practice training in aboriginal and Torres Strait islander health. Med J Aust. 2011;194(11):S67-70.

8. Mayers NR, Couzos S. Towards health equity through an adult health check for aboriginal and Torres Strait islander people: an important Australian initiative that sets an international precedent. Med J Aust. 2004;181(10):531-2.

9. Australian Institute of Health and Welfare. Expenditure on health for Aboriginal and Torres Starit Islander people 2010-11: An analysis by remoteness and disease. Health and welfare expenditure series no. 49. Cat. no. HWE 58. Canberra: AlHW; 2013.

10. Russell LM. Reports indicate that changes are needed to close the gap for indigenous health. Med J Aust. 2013;199(11):737-8.

11. Redfern J, Chow CK. Secondary prevention of coronary heart disease in Australia: a blueprint for reform. Med J Aust. 2013;198(2):70-1.

12. Duckett $S$, Breadon P, Ginnivan L. Access all areas: new solutions for GP shortages in rural Australia. Melbourne: Grattan Institute; 2013.

13. Holman CD, Bass AJ, Rosman DL, et al. A decade of data linkage in Western Australia: strategic design, applications and benefits of the WA data linkage system. Aust Health Rev. 2008;32(4):766-77.

14. Australian College for Emergency Medicine. The Australian Triage Scale. Calton; 2000.

15. Katzenellenbogen JM, Teng TH, Lopez D et al. Initial hospitalisation for atrial fibrillation in Aboriginal and non-Aboriginal populations in Western Australia Heart. 2015;accepted.

16. Teng $\mathrm{T}$, Katzenellenbogen J, Thompson $\mathrm{S}$ et al. Incidence of first heart failure hospitalization, risk factors and outcomes in Aboriginal versus nonAboriginal patients in Western Australia, 2000-2009. Int J Cardio. 2014. 
17. Katzenellenbogen JM, Teng T-HK, Lopez D, et al. First-ever hospitalisation for atrial fibrillation: differentials in risk factors, rates and mortality between aboriginal and non-aboriginal populations in Western Australia 2000-2009. Heart. 2015:0:1-8. https://doi.org/10.1136/heartinl-2014-306678.

18. Thompson SC, Woods JA, Katzenellenbogen JM. The quality of indigenous identification in administrative health data in Australia: insights from studies using data linkage. BMC Med Inform Decis Mak. 2012;12:133.

19. Quan $H$, Sundararajan $V$, Halfon $P$, et al. Coding algorithms for defining comorbidities in ICD-9-CM and ICD-10 administrative data. Med Care. 2005; 43(11):1130-9.

20. Australian Institute of Health and Welfare. Rural, regional and remote health: a guide to remoteness classification, Contract No.: Cat no. PHE 53. Canberra: $\mathrm{ACT} ; 2004$.

21. Geographic Information Systems EB Public Health Division. Department of Health Health Geographical Classification, Version 4.0. Western Australia: Department of Health; 2013.

22. Rasella D, Harhay MO, Pamponet ML, Aquino R, Barreto ML. Impact of primary health care on mortality from heart and cerebrovascular diseases in Brazil: a nationwide analysis of longitudinal data. BMJ. 2014;349:g4014.

23. Levene LS, Baker R, Bankart MJ, Khunti K. Association of features of primary health care with coronary heart disease mortality. JAMA. 2010;304(18):202834.

24. Shi L, Macinko J, Starfield B, Politzer R, Wulu J, Xu J. Primary care, social inequalities and all-cause, heart disease and cancer mortality in US counties: a comparison between urban and non-urban areas. Public Health. 2005; 119(8):699-710.

25. Price E, Baker R, Krause J, Keen C. Organisation of services for people with cardiovascular disorders in primary care: transfer to primary care or to specialist-generalist multidisciplinary teams? BMC Fam Pract. 2014;15:158.

26. Katzenellenbogen JM, Dury A, Haigh M, Woods JA. RuralHealthWest Report: Critical success factors for recruiting and retaining health professionals to primary health care in rural and remote locations. 2013.

27. Durey A, Hill $P$, Arkles $R$, et al. Overseas-trained doctors in indigenous rural health services: negotiating professional relationships across cultural domains. Aust N Z J Public Health. 2008:32(6):512-8.

28. Kiran T, Hutchings A, Dhalla IA, Furlong C, Jacobson B. The association between quality of primary care, deprivation and cardiovascular outcomes: a cross-sectional study using data from the UK quality and outcomes framework. J Epidemiol Community Health. 2010;64(10):927-34.

29. Hunter E, Harvey D. Indigenous suicide in Australia, New Zealand, Canada, and the United States. Emerg Med (Fremantle). 2002;14(1):14-23.

30. National Rural Health Alliance Inc. Australia's health system needs rebalancing: a report on the shortage of primary care services in rural and remote areas. 2011

Ready to submit your research? Choose BMC and benefit from:

- fast, convenient online submission

- thorough peer review by experienced researchers in your field

- rapid publication on acceptance

- support for research data, including large and complex data types

- gold Open Access which fosters wider collaboration and increased citations

- maximum visibility for your research: over $100 \mathrm{M}$ website views per year

At BMC, research is always in progress.

Learn more biomedcentral.com/submissions 